\title{
Research on the Evaluation of Baidu's Enterprise Value Based on DCF
}

\author{
Li-Xin Dai ${ }^{1}$ \\ ${ }^{1}$ Department of Economics \& Management, North China \\ Electric Power University, \\ Baoding City, Hebei Province, China
}

\begin{abstract}
With the rapid development of the Internet economy, Internet enterprise value evaluation has become a hot issue in the area of evaluation. In reference on the basis of the existing research results, take Baidu for example, starting from the angle of enterprise profit model and strategies for the future development, using the most rigorous theoretical basis DCF model to make company valuation.
\end{abstract}

Keywords: Internet; enterprise value evaluation; DCF

\section{INTRODUCTION}

With the rapid development of electronic information technology, the high-tech industry, which is a typical representative of the Internet company, is playing a more and more important role, and has become a pillar industry of the information economy. However, Internet as a high-tech industry, there are characteristics of high risk and high growth. The market financing channels is very simple, the introduction of venture capital, implementation of mergers and acquisitions, listing and financing has become every Internet enterprises to achieve rapid development of as few channels. Therefore, a reasonable assessment of the Internet company value, in achieving the maximization of enterprise value, at the same time, investors receive the recognition, in order to achieve financing and M \&amp; A, and ultimately to achieve Internet companies continue to leapfrog growth. It can be said that the value of the Internet company is the basis for the effective operation of the Internet Co financing for investment activities, the basis for the decision making.

\author{
Zhan-Peng Cui ${ }^{1}$ \\ ${ }^{1}$ Department of Economics \& Management, North China \\ Electric Power University, \\ Baoding City, Hebei Province, China
}

In this paper, the Baidu Inc is chosen as the research case, and it is based on the DCF evaluation model to evaluate the value of the study, in order to provide a reference for the evaluation of the value of the China Internet Corporation. Select the main reasons for the case of the case of Baidu as the market value of the domestic Internet Co ranked third, ranked sixth in the Global Internet Company, is a more mature Internet listed companies. In view of Baidu in the mature period of enterprise life cycle, this paper in a profound analysis based on the current situation of the development of Baidu, taking into account the baidu company's future development strategy, the final selection of theoretical framework of the most scientific and rigorous cash flow discount model of Baidu company value assessment, despite some limitations, but compared to the and other assessment methods did a more comprehensive and accurate assessment of the value of.

\section{DCF Model}

Discounted cash flow method, is the future of the enterprise cash flow and its risk is expected, and then choose a reasonable discount rate, the future cash flow into the present value. The key of this method was used to determine: first, the cash flow of the enterprise expected future duration each year; the second to find a reasonable fair discount rate, discount rate depends on the risk of future cash flows, the greater the risk, the requirements of the discount rate is higher; and vice versa vice.

Discounted cash flow model (DCF model) is mainly divided into 3 parts: the estimation of capital cost, the 
calculation of free cash flow and the final value of the final phase of the company.

\subsection{Estimating Capital Costs}

Discounted cash flows should reflect the inherent risk of future cash flows, the most widely used weighted average cost of capital (WACC), the formula is as follows:

$$
W A C C=K_{\mathrm{b}}\left(1-T_{c}\right) \frac{B}{V}+K_{S} \frac{S}{V}
$$

Where:

$\mathrm{K}_{\mathrm{b}}$ is the cost of debt;

$\mathrm{K}_{\mathrm{s}}$ is the cost of equity;

$\mathrm{T}_{\mathrm{c}}$ is corporate tax rat;

$\mathrm{B} / \mathrm{V}$ is the percentage of financing that is equity;

$\mathrm{S} / \mathrm{V}$ is the percentage of financing that is debt.

The cost of equity capital, Ks, can be understood as the opportunity cost of equity providers. That is the return of the shareholders' rights and interests. The capital asset pricing model (CAPM), which is the most common use of equity capital, is as follows:

$$
E\left(R_{\mathrm{i}}\right)=R_{f}+\beta\left(E\left(R_{\mathrm{m}}\right)-R_{f}\right)
$$

where:

$E\left(R_{i}\right)$ is the expected return on the capital asset;

$\mathrm{R}_{\mathrm{f}}$ is the risk-free rate of interest such as interest arising from government bonds;

$\beta$ is the sensitivity of the expected excess asset returns to the expected excess market returns;

$\mathrm{E}\left(\mathrm{R}_{\mathrm{m}}\right)$ is the expected return of the market;

$E\left(R_{m}\right)-R_{f}$ is known as the risk premium.

\subsection{FCFF Model in two Stages}

When calculating free cash flow, the company's future can be divided into two stages, which can clearly predict the value of the enterprise and the evaluation period of the final value. The forecast clearly the corporate value of the free cash flow according to independent years reasonable prediction; for the period of assessment of final value means predicting future infinite during every year of free cash flow is a difficult and inaccurate. Therefore, the calculation of a final value, equal to the value of the discounted free cash flow of the enterprise can be clearly predicted after the period of enterprise value.

$\mathrm{FCFF}=\mathrm{EBIT}(1-\mathrm{t})+$ Depreciation

- Change in Investments

- Capital expenditure

Where:

EBIT is the earnings before interest and taxes.

Then the enterprise value is:

$$
\begin{gathered}
\text { Enterprise Value }=\sum_{t=1}^{\mathrm{n}} \frac{F C F F_{t}}{(1+W A C C)^{t}} \\
+\frac{F C F F_{n+1} /\left(W A C C-g_{n}\right)}{(1+W A C C)^{n}} \\
=\sum_{t=1}^{\mathrm{n}} \frac{F C F F_{0}(1+g)^{t}}{(1+W A C C)^{t}}+\frac{F C F F_{n+1} /\left(W A C C-g_{n}\right)}{(1+W A C C)^{n}}
\end{gathered}
$$

where:

$F C F F_{t}$ is the free cash flow of the enterprise as expected of the year $\mathrm{t}$;

$F C F F_{0}$ is the free cash flow of enterprises in the early period;

$F C F F_{n+1}$ is the free cash flow of the enterprise at the end of the year $n+1$;

$g$ is the exceptional returns in the first n years;

$g_{n}$ is the stable growth rate after $\mathrm{n}$ years;

$W A C C$ is the capital weighted average cost.

\section{DCF model in the application of Baidu Inc}

\subsection{Analysis of current situation and future} development strategy of Baidu

In the current Chinese search market dominance of Baidu, which faces the future revenue growth and the declining profit rate reduced, to maintain a high growth rate, we must find out the most value growth opportunities for the 
enterprise. Expand existing products and services market share, develop new products and markets and mergers and acquisitions, corporate value will continue to increase to make Baidu to continue in a favorable position in the market competition, in the capital market to maintain highly attractive.

Through the analysis of the results of the past 5 years Baidu earnings data, Baidu nearly 5 years of development is very rapid, revenue growth rate is amazing. Revenue growth was the fastest in the 2010 to 2012, the average annual growth of more than $50 \%$. Baidu's total revenue in 2014 was 49052000000 yuan (about 7906000000 U.S. dollars), up $53.6 \%$ in 2013. Baidu's revenue growth the main reason lies in the network marketing is the attention of many domestic enterprises, while Baidu has occupied the main entrance of the search, which is also the achievements of the Baidu's revenue and its corresponding value. Baidu 2014 network marketing revenue of 48495000000 yuan (about 7816000000 U.S. dollars), up 52.5\% over 2013. But from the point of view of the proportion of growth in 2013, began to decline, the main reason lies in a is total revenue base increased the growth rate began to decline. Second, other market competition makes revenue split, especially the competition in the mobile terminal. And in December 2014, baidu comes from in the mobile terminal of search revenue for the first time in more than a PC, the strong performance of the mobile performance for 2014 revenue growth accelerated the formation of a support, mobile investments in the past two years has made obvious achievements, and Baidu seize greater market opportunities erection stage.

\subsection{Calculation of Cost of Capital}

According to Equation 2-1, the most widely used of the weighted average cost of capital (WACC) is calculated as follows:

$$
W A C C=K_{\mathrm{b}}\left(1-T_{c}\right) \frac{B}{V}+K_{S} \frac{S}{V}
$$

(1) $\mathrm{Kb}$ is taking the Central Bank include 3-5-year benchmark loan rate $5.9 \%$.

(2) Tc is taking a $25 \%$ income tax rates.
(3)By looking at the earnings of Baidu in 2014, total liabilities of 48.136 billion yuan, total shareholders ' equity of 51.526 billion yuan, calculated that debt value weight and shareholder value were $48.3 \%$ and $51.7 \%$.

(4) The cost of equity capital $\mathrm{Ks}$, according to the formula (2) capital asset pricing model (CAPM):

The cost of equity capital $=$ risk-free return $+\beta$ coefficient $*$ market risk premium.

Risk-free return issued in October 2014 5-year fixed-rate interest-bearing bonds coupon rate $5.41 \%$.

Beta coefficient on Baidu stock provided by the NASDAQ stock market fluctuations and calculate the beta factor of 1.53 .

$\beta$ coefficient adopted on Baidu stock fluctuations calculated by NASDAQ stock exchange market of 1.53 .

Market risk premium $=$ market risk rate of return-risk-free rate of return. Market risk rate of return is using the September 30, 1994 to September 30, 201420 years, the NASDAQ 100 index (NASDAQ 100 Index is representative of the US high-tech stocks, the 100 constituent stocks of the index are high-tech, high-growth and non-financial characteristics, covering Apple, Microsoft, Intel, Baidu and other well-known companies) the average annual yield of $12.36 \%$; Finally conclude the market risk premium $=12.36 \%-5.41 \%=6.95 \%$.

Calculate the cost of equity capital $\mathrm{Ks}=5.41 \%+1.53 *$ $6.95 \%=16.04 \%$

Finally, according to the formula 2-1, calculated

$\mathrm{WACC}=5.90 \% *(1-25 \%) * 48.30 \%+16.04 \% * 51.70 \%$ 0.02137275

\subsection{Forecast of Baidu's future free cash flow}

According to the status and future development of Baidu's corporate strategy, the author divide Baidu's future development into three stages:

The first stage is a direct forecast period, which 2015--2017 years will be rapidly developed, forecasting its 2015 revenue growth of $43 \%$ year on year, an increase of 45 percent in 2016, an increase of 38 percent in 2017. 2018--2022 years for a steady growth, maintaining an average annual increase of about $30 \%$. 
The second stage is 2022 to unlimited long-term for the end of the value evaluation period, in the long run, for a company or industry, the expected future free cash flow growth rate is unlikely to exceed GDP growth in the future, but as an Internet company, continuously high growth and finding a new growth pole is its lifeline, so it is possible to set a long-term growth rate of $5 \%$ of Baidu.

According to historical data of Baidu earnings disclosed over the years to analyze, and thus to determine the forecast of the reference value of the company's future free cash flow .

First, estimate the present value of cash flows of the enterprise value period (2015--2022 year).
According to the company free cash flow formula, corporate free cash flow $=\mathrm{EBIT}+$ depreciation - income tax - capital expenditures - net working capital increase $=$ NOPAT - net investment, where net investment = capital expenditures + net increase in working capital-depreciation. Income tax rate of $25 \%$, but after adjustment, the effective tax rate of only $15 \%$ of pre-tax profit of interest, for simplicity, each year in accordance with EBIT of $15 \%$ income tax, while assuming depreciation, capital expenditures, the net increase in working capital and the ratio of operating income to maintain the same growth.

Table 1. 2014-2022 forecast the present value of FCF.

Unit : 100 million RMB

\begin{tabular}{|c|c|c|c|c|c|c|c|c|c|}
\hline Year & $2013 \mathrm{~A}$ & $2015 \mathrm{E}$ & $2016 \mathrm{E}$ & $2017 \mathrm{E}$ & $2018 \mathrm{E}$ & $2019 \mathrm{E}$ & $2020 \mathrm{E}$ & $2021 \mathrm{E}$ & $2022 \mathrm{E}$ \\
\hline Income & 490.52 & 701.44 & 1017.09 & 1403.58 & 1824.66 & 2372.06 & 3083.67 & 4008.78 & 5211.41 \\
\hline Revenue growth & $53.60 \%$ & $43 \%$ & $45 \%$ & $38 \%$ & $30 \%$ & $30 \%$ & $30 \%$ & $30 \%$ & $30 \%$ \\
\hline EBIT & 144.75 & 206.99 & 300.14 & 414.19 & 538.45 & 699.98 & 909.98 & 1182.97 & 1537.86 \\
\hline + Depreciation & 22.23 & 31.79 & 46.09 & 59.92 & 77.90 & 101.27 & 131.65 & 171.14 & 222.49 \\
\hline -Taxes & 22.32 & 31.92 & 46.28 & 63.87 & 83.03 & 17.96 & 140.32 & 182.41 & 237.13 \\
\hline -Capital expenditures & 63.95 & 91.44 & 132.60 & 172.38 & 224.09 & 291.32 & 378.72 & 492.34 & 640.04 \\
\hline -Change in Investments & 32.49 & 46.46 & 67.37 & 92.97 & 120.86 & 157.12 & 204.25 & 265.53 & 345.18 \\
\hline FCF & 48.22 & 68.96 & 99.98 & 144.89 & 188.37 & 334.85 & 318.34 & 413.83 & 538.00 \\
\hline WACC & - & $10.43 \%$ & $10.43 \%$ & $10.43 \%$ & $10.43 \%$ & $10.43 \%$ & $10.43 \%$ & $10.43 \%$ & $10.43 \%$ \\
\hline Discount factor & - & $90.55 \%$ & $82.00 \%$ & $74.25 \%$ & $67.24 \%$ & $60.89 \%$ & $55.14 \%$ & $49.93 \%$ & $45.21 \%$ \\
\hline
\end{tabular}

The second step, the estimated final value of the present value of cash flows.

(1) The 2022 year-end estimate of value.

Final worth

$$
\begin{aligned}
T V & =F C F_{\mathrm{t}+1} /(W A C C-\mathrm{g})=564.90 /(10.43 \%-5 \%) \\
& =10403.31
\end{aligned}
$$

(2) the present value of 2022 year-end estimate of value.
The present value of the Final worth :

$$
T V_{0}=T V /(1+W A C C)^{\mathrm{t}}=12873.14 /(1+10.43 \%)^{8}
$$$$
=4704.08
$$

The third step is to estimate the value of Baidu's business.

Baidu's enterprise value $=$ enterprise value can be clearly predicted the present value of cash flows + final value of 
cash flow present value $=147.165+470.408=617.573$

billion yuan

Baidu value per share $=$ enterprise value / equity $=$ 617.573 billion yuan $/ 0.350$ billion shares $=1764.49$ yuan $=$ 284.39 dollars

\section{Analysis of the Differences of Baidu's Valuation}

According to DCF model, a reasonable value of Baidu's current worth is 284.39 dollars, and share price was 197.24 dollars at July 2 in 2015, so the market value is relatively undervalued. From April 2014, Baidu's stock prices weekly cases (data from Sina Finance) are shown in Figure 1.

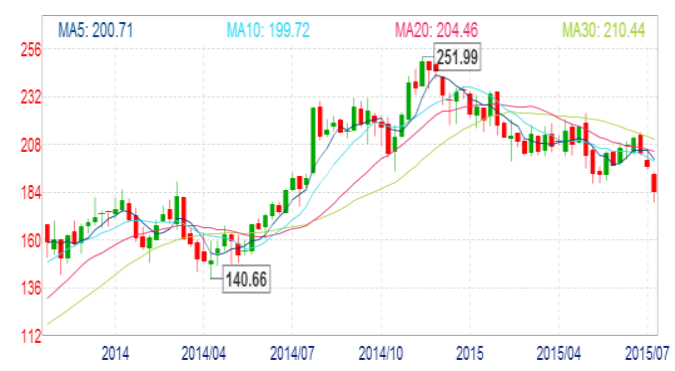

Fig.1. movements of Baidu's stock price

Observing Baidu's recent stock price, Baidu's shares are all the way up from April 2014, until November 21, 2014 reaching 251.99 dollars, then trend became weakening.

\section{Conclusion}

Thus, using the theoretical framework of the most rigorous DCF model to estimate the value of Internet companies is feasible, mainly by analyzing the business models of the Internet industry, the overall characteristics of the industry, the company's historical financial data and the company's future development strategy, the Internet company's future cash flows do a more reasonable forecast, through the scientific method to calculate the discount rate more accurate business valuation made to achieve a certain degree of rationality and accuracy. Finally through analysis of the difference between the evaluation and market value, help to understand the intrinsic value of the enterprise, corporate mergers and stock price provides a basis, while the majority of investors It provides a more reliable reference.

\section{Acknowledgments}

Social sciences research project of the people's livelihood in Hebei Province, " Research on sustainable development and social responsibility management of thermal power enterprises in Hebei Province ". Number: 201501516.

\section{References}

[1] Guchun Xiang, comparative study of two methods of business valuation $[\mathrm{J}]$. China Township Enterprises Accounting.2007 (03).

[2] Zhu Yinhua research use Black-Scholes valuation model in the enterprise [J]. Value Engineering. 2007 (04).

[3] Ren Wenlong, Sun Hongbin, post forest, yellow sunflower. On the Value of business valuation probability interval [J]. Economic Forum.2009 (11).

[4] The method of valuation of high-tech enterprises of Yang double pigeon. [J]. ECONOMICS. 2008 (10). 